\title{
Evaluation on Degree and Result of Bilingual Education of Business Courses in GDUFS
}

\author{
Yong Jiang ${ }^{1}$ \\ ${ }^{1}$ School of International Trade and Economics, Guangdong University of Foreign Studies, China \\ Correspondence: Yong Jiang, School of International Trade and Economics, Guangdong University of Foreign \\ Studies, Guangzhou, China. E-mail: jiangyong@gdufs.edu.cn
}

Received: April 14, 2013 Accepted: April 30, 2013 Online Published: July 4, 2013

doi:10.5539/elt.v6n8p175 URL: http://dx.doi.org/10.5539/elt.v6n8p175

The research is supported by Research Funding of Center for Canadian Studies (B2013CCS14) of GDUFS, China Postdoctoral Science Foundation funded project and Education Research Project for Young Schoars in Guangdong University of Foreign Studies (GWJYQN11001).

\begin{abstract}
From the connotation of bilingual education in higher education in China, this paper analyzes the factors that may affect the quality and result of bilingual education, such as faculty and students' English level, teaching materials, curriculum system, classroom instruction, teaching quality control, as well as incentives and other factors. The paper focuses on Fuzzy-AHP model as a university bilingual education quality evaluation system, and build an evaluation index system for quality control of bilingual teaching. It also conducts quantitative analysis using analytic hierarchy process and fuzzy comprehensive evaluation on the degree of the bilingual education of business courses in Guangdong University of Foreign Studies (GDUFS), China. By selecting evaluation indicators and using analytic hierarchy process, the paper determines corresponding weight of the indicators. It also establishes sets of standard on evaluation and fuzzy relationship matrix, and conducts an empirical study on the degree of bilingual education of business courses in GDUFS. The paper has certain theoretical and practical significance for bilingualism in higher education in China.
\end{abstract}

Keywords: bilingualism, business courses, degree of bilingual teaching, evaluation

\section{Introduction}

Currently, the research on bilingual education includes the following fields: theoretical exploration of bilingual education, bilingual teaching mode, international comparison of bilingual education, curriculum design in bilingual education, teaching materials for bilingual education, teacher training in bilingual education and evaluation on the classroom teaching for bilingual education. There are three main modes in the bilingual teaching: immersion bilingual education, transitional bilingual education and conservative bilingual education. Lack of immersive language environment for bilingual teaching, bilingual education in China only applies to part of the discipline in some universities, and it belongs to transitional or conservative bilingual education. According to English teaching situation in China and English language proficiency and ability of university students in China, Fan.et al (2006) proposes to classify bilingual teaching modes into three categories: half-English, mixed-English, all-English from the view of gradual acceptance of degree of English usage in class. This series of bilingual teaching modes define a gradual process from the unfamiliarity to the familiarity of English way of thinking for students, and also reflects the psychological development of Chinese way of thinking to the English way of thinking.

In bilingual education practice of business courses in GDUFS, the following problems are detected: Firstly, ineffective implementation of bilingual teaching in the course teaching. Students may not grasp the necessary knowledge of related subject, nor can they broaden the vision of disciplines and understand recent development of the subject. Secondly, language learning has ineffective results. Students can not improve the ability to use English, and cannot develop good habits of English way of thinking. Thirdly, in general, goals of bilingual education are difficult to be achieved. With poor learning environment, students learning enthusism has been gradually reduced, and cross-cultural and innovation abilities of student cannot be substantially improved. The 
degree and proportion of usage of English may be one of the important reasons for the above problems. Analysis of degree of bilingual education is an essential part of the research of bilingual education, and it is also a refinement of the specific mode on bilingual teaching.

The first teaching objective of bilingual education is clear: the language of instruction is only a tool, not the educational purposes for bilingual education. This is particularly important for business courses. The teaching quality of the course cannot be reduced only because it uses English as the medium of instruction. In the selection of materials, the course adopted a method of combining Chinese textbook and classic English teaching materials and also assisted with some of current reading material, enabling students to understand the latest developments in business. By reading real business cases in English, learning boring business theory becomes vivid. Students are trained to learn theoretical knowledge in English and improve their ability in business at the same time.

English level is a basic requirement in the selection of students to ensure the quality of bilingual teaching, the professional interests of students on economics should also be paid attention to. Our university has advantages in foreign language resources, because students generally have more solid foundation in English, which also created conditions for the implementation of bilingual teaching. Bilingual teaching classes are smaller in size so that the quality of teaching and full of class discussion are maintained.

\section{Literature Review}

Research on bilingual evaluation model is built on the basis of educational evaluation systems, which mainly include: Taylor mode, CIPP evaluation mode, target-free evaluation mode, developmental objective evaluation mode. Taylor mode on evaluation takes behavioral objectives as a focus, and regard special achievements of students as the goal of the education program and plans. This goal is also taken as the main basis of the evaluation and direction of education in the educational process. According to this model, the educational evaluation is a measure to the extent that actual activities achieve educational goals. Considering the disadvantage of Taylor evaluation mode, CIPP evaluation mode was proposed in 1966. It is to make up for the weakness of Taylor, which does not target its own evaluation and put more weight on results rather process. However, CIPP emphasizes more on with quantitative targets while ignoring qualitative targets, which resembles the Taylor mode to a certain extent.

Sang (2010) applies neural-network method to the evaluation of bilingual education, and create a BP neural network model. RBF neural network is a feed-forward back-propagation network, which consists of three layers. The input layer nodes pass the input signal to the hidden layer, and then from hidden layer to radial grassroots. The basic functions of hidden nodes are distance functions and regard the base functions of diameter as an activation function. The output layer is a linear layer, wherein $\mathrm{P}$ is the input matrix, $\mathrm{S} 1$ is the radial base number of neurons; IW is radial primary matrix for weights; b1 stands for the radial primary threshold value; AL radial grassroots output; LW weights of the output layer; b2 is output layer threshold. Based on these asumptions, Rao (2009) design a bilingual education evaluation RBF network structure. Zhu (2008) utilizes the Analytic Hierarchy Process (AHP) to calculate the index weights and Fuzz matrix for potential evaluation, thus establish the Fuzzy-AHP evaluation model of bilingual education. D-AHP a bilingual evaluation model tends to use a method of combining of the analytic hierarchy process and expert consultation. Analytic Hierarchy Process (Analytical Hierarchy Process), also known as parsing hierarchical process, divided the various constituent elements of the problem into orderly hierarchy of interrelated factors, and it gives number of calibration on the composition of the various levels according to their relative importance, and then use rigorous mathematical methods to process, obtaining quantitative results of the importance of each factor (weight value) as calibration values. Problems are finally analyzed and solved by sorting through the results.

There are plenty of research on the influencing factors on bilingual education and bilingual education evaluation indicators in China, which can be summarized as follows. (a). There are abundant papers in normative research, such as Zhang et al (2007). (b) Empirical research is less concerned about comprehensive influence of all factors', such as Yang (2007) and Liu et al (2007), Huang (2007), Jia (2008). Yang et al (2005) proposed a communicative evaluation mode that mainly based on "teaching \& learning" module. Chen (2006) presents the current development trend of the educational evaluation, situation of bilingual education in China and advantages of foreign evaluation mode. He also proposes developmental and objective evaluation mode of bilingual education. Various evaluation modes are established in accordance with its ordered arrangement of different levels of indicators. However, it is undeniable that some evaluation modes completely rely on fuzzy math or neural network theory, thus ignore the subjective factors and the characteristics of bilingual teaching and learning mode. They only exert full evaluation mode by mathematical modeling or communication network, 
which is the apparent deviation from the original intention of bilingual education evaluation. So the current research should achieve the refinement of the indicators, with the dedicate design of the questionnaire survey to establish an evaluation index system to measure the effectiveness bilingual education to achieved significant results on bilingual education.

\section{Research Method}

By questionnaires, gray correlation analysis, data envelopment analysis (DEA) method, reasonable assessment of the curriculum, teaching quality and the effectiveness of bilingual education is made. Results will be assessed to evaluate whether a course should be applied with bilingual teaching, as well as determine degree of bilingual education, namely, how much proportion the tutor should use English in the whole course teaching. A variety of factors, which influence the degree of bilingual education, can be divided into five categories: overall quality and professionalism of teachers, foreign language proficiency and professional basis of students, point of view on bilingual education on future development, education management and learning environment.

Common factor ONE mainly reflects support for the faculty, which includes sufficient degree of quality of bilingual education teachers, evaluation on bilingual education teachers level, professional quality evaluation on bilingual teachers, evaluation on the level of English communication of teachers, the time that teacher spend on answering the students' questions after class, teaching methods and other indicators. It can be named as "teacher quality factor", ranging from the overall level of professionalism of the faculty to teachers' foreign language proficiency.

Common factor TWO mainly reflects foreign language proficiency and knowledge foundations of students, including learning burden resulted from bilingual education, the degree of understanding during the teaching process of bilingual programs, time allocation on extracurricular learning, and the different English level of the same course between regular class students(courses instructed in Chinese) and bilingual students, whether use English way of thinking in daily communicaiton, the appropriateness of using bilingual teaching in the courses, and the follow-up effects of bilingual education classroom teaching. So it can be named as "student quality factor".

Common factor THREE included whether bilingual education will help learning business knowledge on the entire undergraduate program, whether bilingual programs help further study or work of students, whether it is necessary to conduct bilingual education in China, together with people's view on the trend of bilingual education China, etc. Those elements can be summarized as "factor of students' expectation" because these indicators reflect the psychological expectations of students in bilingual teaching. They expect that their career development can be beneficial from the learning ability improvement due to bilingual education, and this factor also reflected more requirements for bilingual education for university students in the social trends with huge employment pressure under the situation of globalization.

Common factor FOUR reflects the bilingual education management, including curriculum design, textbook selection, and course assessment methods. Many other factors are also embodied in the following indicators: whether enough bilingual teaching courses are offered by the university, view on the bilingual teaching curriculum design, rationality on specific bilingual teaching course, the difficulty of teaching materials to fit the needs in bilingual teaching for Chinese business undergraduate students, the richness of the course materials, the appropriate examination method of bilingual courses, and the ratio of homework that must be completed in English.

Common factor FIVE includes bilingual learning atmosphere, adequacy of extracurricular activities in English, willingness to participate in extracurricular activities in English, satisfaction of the students on these activities, usage of English in routine communication among classmates, the appropriate level of these extracurricular activities, and other indicators. These elements can be summarized as "learning environment factors", which can be further divided into macro-environment and micro-environment. Divided contribution rate variance of the public factors by the cumulative contribution rate, the weight of the key factors can be obtained, thus evaluation index system on the bilingual education can be formed.

The rationale of using the method combining the use of the analytic hierarchy process with fuzzy comprehensive evaluation shows in three aspects: Firstly, the use of the analytic hierarchy process method to quantify and calculate "the degree of bilingual education" will overcome the shortcomings of one-sidedness, blurs by other method that can be selected. Secondly, the checking process on the calculation consistency can ensure scientific and reasonable index weights, thus it makes test evaluation results more accurate. Finally, the combination of fuzzy comprehensive evaluation in the research method can well achieve the research purpose of this paper, which is to determine that specific degree of bilingual education in business courses in GDUFS. 
Firstly, impact factors on the evaluation of "degree of bilingual education" should be determined. In order to make the evaluation factors more reliable and valid, the judgment matrix of evaluation factors is established based on their importance. And then AHP is use to determine the weight of each factor. At last, fuzzy comprehensive evaluation method is applied to quantitative analysis of degree of bilingual education. The detailed steps are as follows:

(a). Construct comparative judgment matrix. The comparative judgment matrix is defined as ${ }^{A}=\left\{a_{i j}\right\},(i, j=1,2,3, \ldots, n)$, in which ${ }^{a_{i j}}$ is regarded the target element $A$ as the criteria, and determined by the pairwise comparisons among the criteria level elements. The method adopts the judgment scale of Satty as the 1 to 9 scale.

(b). Comparative calculation the weights of judgment matrix and checking on the consistency. Make comparative judgment on the feature vectors $W$ of the matrix, and $W$ is the vector of relative importance of the various elements. Using the normalization process, each comparative judgment matrix eigenvalue and eigenvectors can be calculated, thus reults is drawn according to the level single sort weights $W$, largest eigenvalue $^{\lambda_{\max }}$, consistency value C.I. and consistency ratio C.R. If necessary(when C.R. $>0.1$ ), results should be amended in accordance with the given consistency indicators correction method by Satty.

(c). Establishment of the review set. This study set fuzzy evaluation grade as $V=\left(V_{1}, V_{2}, V_{3}, V_{4}, V_{5}\right)$, which stands for the five levels of bilingural teaching, which are excellent in quality, high in quality, fair in quality, low in quality, poor quality respectively, and different evaluation grades are assigned to different value.

(d). Establishment of fuzzy evaluation matrix for each evaluation set. Fuzzy evaluation grade can determine the degree of affiliation $r_{i j}(i=1,2,3 \ldots n ; j=1,2,3 \ldots n)$. The difference between actual value of indicators and standard value has a linear relationship with the degree of affliation. That is, if the actual value of indicators equal to the standard value of the evaluation set of the indicators elements, the affliation degree of this set of elements evaluation is equals to one; if the actual value of indicators deviates from the standard value of the evaluation set of the indicators elements, the affliation degree of this set of elements evaluation would become strictly less, so affiliation degree beyond this boundary equals to zero. There is a corresponding vector $R=\left\{r_{i 1}, r_{i 2}, r_{i 3}, r_{i 4}, r_{i 5}\right\}$ associociated with the degree of affliation to reflect ${ }^{i}$ th evaluation index. Thereby the value of each layer affiliation degree can be obtained as:

$$
R=\left(\begin{array}{ccc}
r_{11} & \ldots & r_{15} \\
\vdots & \ddots & \vdots \\
r_{n 1} & \cdots & r_{n 5}
\end{array}\right)
$$

(e). Calculate the fuzzy evaluation vector using synthetic arithmetic method on fuzzy matrix, and comprehensive evaluation model is expressed as $B=W_{o} \times R$, where $O$ indicates the fuzzy operator. This paper uses the weighted average method, that is $B_{j}=\sum_{i=1}^{n} A_{i} \times R_{i, j}$. If $\sum_{j=1}^{j_{m} B_{j} \neq 1}$, the normalization process is conducted. For a multi-level system, evaluation results are calculated on recursive level indicators from the bottom up. Based on this method, the calculated score value is recursive upward to the target layer.

(f). Calculate "the degree of bilingual education". According to the fuzzy integrated vector $B$, the degree of bilingual education is obtained. The value ${ }^{b=\max _{1=\leqslant s}\left\{b_{j}\right\}}$ is traced to the affiliation function, and the corresponding values of degree of bilingual education are finally obtained.

\section{Results}

As can be seen from the establishment of first-level indicator and contribution rate of variance, teachers and students remain their key role in bilingual education, which coincides with the results of existing research. 
However, it should be noted that the quality of the teachers and students cannot be isolated and separated, and interaction between the two parties remains a more important issue. In addition, it can be found out that the psychological expectation of bilingual education in improvement of learning ability and future career development elevated to a more important position, even more important than teaching management and teaching environment. All these indicate that it is society's demand that spur students' enthusiasm for bilingual learning, while the implementation of bilingual teaching reform is widely recognized and supported by the society, which conforms to the trend of social development in globalization.

The affiliation function of the nature of business courses can be written as,

$$
r_{v 1}(x)=\left\{\begin{array}{c}
1, X \geq V_{1} \\
\frac{X-V_{2}}{V_{1}-V_{2}}, X \in\left[V_{2}, V_{1}\right] \\
0, \text { otherwise }
\end{array}\right.
$$

The results of other factors can also derives following the same rule, so the matrix for fuzzy relationship is,

$$
R=\left[\begin{array}{lllll}
r_{11} & r_{12} & r_{13} & r_{14} & r_{15} \\
r_{21} & r_{22} & r_{23} & r_{24} & r_{25} \\
r_{31} & r_{32} & r_{33} & r_{34} & r_{35} \\
r_{41} & r_{42} & r_{43} & r_{44} & r_{45} \\
r_{51} & r_{52} & r_{53} & r_{54} & r_{55} \\
r_{61} & r_{62} & r_{63} & r_{64} & r_{65} \\
r_{71} & r_{72} & r_{73} & r_{74} & r_{75}
\end{array}\right]=\left[\begin{array}{ccccc}
2 / 3 & 1 / 3 & 0 & 0 & 0 \\
0 & 1 / 2 & 1 / 2 & 0 & 0 \\
1 / 3 & 1 / 3 & 1 / 3 & 0 & 0 \\
1 / 3 & 2 / 3 & 0 & 0 & 0 \\
0 & 1 & 0 & 0 & 0 \\
1 / 2 & 1 / 2 & 0 & 0 & 0 \\
1 / 4 & 1 / 2 & 0 & 1 / 4 & 0
\end{array}\right]
$$

The fuzzy vector of business courses can be calculated as:

$$
\begin{aligned}
& B=W_{o} \times R=(0.35,0.11,0.24,0.16,0.14,0.23,0.32) \times R \\
& =(0.558,0.8337,0.135,0.08,0)
\end{aligned}
$$

Based on the above results: $b=\max \{0,558,0.8337,0.135,0.08,0\}$. Thus the level of "excellent in quality" has the highest degree of affiliation. The value of $b$ will be brought into the affiliation function ${ }^{r_{22}}(x)$ to obtain the degree of bilingual education of business courses is 0.7667 .

Based on the comprehensive evaluation of various factors, the degree of bilingual education of business courses in GDUFS is $76.67 \%$, which means that those major business courses that tend to be bilingual education, above seventy-six percent of the instruction language is English.According to results of the degree of bilingual education of 76.67\%, business schools of Guangdong University of Foreign Studies insist on the reform of bilingual education and teaching practice using English instruction for business courses. Teachers keep the proportion of English instruction from 50\% to $90 \%$, only supplemented by a small amount of Chinese for theoretical explanation. In the teaching process, the teachers and students have perfect interactions, with high the enthusiasm of the students in bilingual learning. At the end of the course, professional knowledge test is conducted to students by the teachers and the results are great (there is a detailed empirical test for the learning results in the later part of the paper). Finally, students' satisfaction with the business courses of "bilingual teaching" is surveyed in form of questionnaire, and survey results shows that students are generally satisfied with the overall assessment of the bilingual business courses.

In theory, the range of degree of bilingual teaching in a foreign language is from $0 \%$ to $100 \%$, but above-mentioned range of $(30 \%, 80 \%)$ is recommended as proper theoretical ratio based on the specific teaching practice. For the vast majority of courses, the chapter names, combined with the basic concepts for building a curriculum system and the terminologies usually accounts for $15 \%-20 \%$ in business courses. And these basic concepts and terminology should not be taught in English. The basic principles and concepts course should be explained bilingually considering the actual situation of the specific course and these contents account for at least $20 \%$ of the course. Therefore, the actual degree of bilingual teaching instructed in English should not be 
less than $30 \%$. On the other hand, when teachers used entirely or the vast majority of space and time delivering courses in a foreign language, that means no or only a small part of courses is explained in the mother tongue. This results in a very high level of language mastery for students who involve in the bilingual education and they need more solid foundations for English language in the first two years of study for their college education.

\section{Evaluation on Empirical Results}

Assessment on bilingual teaching for business courses is complex and diverse. The assessment can be roughly divided into two parts: performance in class and test scores. The former usually refers to attendance rate, participation in class, as well as performance in presentations. Evaluation from this aspect is inclined to have certain degree of subjectivity, the aim of which is to promote students to participate in learning and discussion. For example, at the beginning of the course, teachers will make a detailed description of the course, and then let the students choose topics according to their own interests, so that each student can focus on a topic. And extracurricular reading material will be prepared by the teacher to help students have a comprehensive understanding of the knowledge. Presentation time is strictly controlled within five minutes, and presenting all content in English will improve students' English skills. Teachers will evaluate the performance of the presentations and calculate score in results.

Examination method can also be divided into objective quizzes and narrative tests. On the whole, objective test will ocupy relatively less in the final mark. The course exam is comprehensive test, including teacher lectures, research findings of students and content of presentation. Because the courses are "bilingual", examinations form has its particularity, which a combination of objective tests and narrative test are utilized. In order to study the difference between same courses that teaching in bilingual module and traditional module totally in Chinese, all exams and test results were carefully recorded, and survey is also conducted as research supplement. These results are recorded as the original data of teaching and education research. Empirical effectiveness of bilingual teaching is modeled with discrete variables (binary choice). The value of variable (FS) equals to 1, representing that test scores are improved in the group of students who received bilingual education. On the contrary, value of 0 represents no improvement. The main explanatory variables include XFF, PJF, CYF, which XFF stands for whether students accept the bilingual teaching module, acceptance is represented by 1 , and 0 indicates rejection. PJF is weighted average exam scores of the students. CYF is students' test score. The following equation is applied to analyze the effect of bilingual teaching:

Probit model based the standard normal distribution can better fit the function, The obtained data and survey results are involved, and the regression equation and related results are calculated as:

$$
\begin{gathered}
\hat{y}_{i}^{*}=-24.5935+2.1475 P J F+0.0312 C Y F+1.7536 X F F \\
(-2.81) \quad(2.75)
\end{gathered}
$$

Distribution function is fit for Logit model, the regression equation and results is calculated as:

$$
\begin{aligned}
\hat{y}_{i}^{*}= & -36.743+3.1264 P J F+0.0516 C Y F+2.8412 X F F \\
(-2.70) & (2.53)
\end{aligned}
$$

If Extreme model is adopted, the result is

$$
\begin{array}{r}
\hat{y}_{i}^{*}=-23.645+2.0316 P J F+0.04 C Y F+1.8612 X F F \\
(-2.74)
\end{array}
$$

Interpretation of the coefficients in the discrete variable model is very complex. The results of the model cannot explain the marginal effects of the dependent variable, so it only can be analyzed through the conditional probability analysis of the marginal impact of ${ }^{X_{j}}$ :

$$
\frac{\partial E(y \mid x, \beta)}{\partial x_{i}}=f(-x \beta) \beta_{i}
$$


Considering coefficients in Probit model in equation (3), bilingual teaching methods affect the probability, and the achievements can be given by:

When $X F F=0$,

$$
P(F S=1)=\Phi(-24.5935+2.1475 P J F+0.312 \times 81.745)
$$

When $X F F=1$,

$$
P(F S=1)=\Phi(-24.5935+2.1475 P J F+0.312 \times 81.745+1.72)
$$

The average test score is 81.745 for bilingual business courses. Calculated by the formula, XFF has greater probability for the achievement of the bilingual study, thus probability of acceptance of bilingual teaching performance improvement is significantly higher than those of rejection. The most direct result is to increase the students' ability to speak English with professional thinking and competitiveness in the job market, so that students can get a favorable position in finding work, dealing with the written test and interview in the job hunting. The paper tries to explore the course content, process and atmosphere for bilingual teaching mode for business courses in all aspects, thus to help students expand their horizons in learning, cultivate innovative talents, and enhance students' competitiveness in the job market.

After education reform for bilingual education, the bilingual teaching of GDUFS has achieved remarkable results, the outstanding quality of the training has been recognized by universities, education administrative authorities and the community as well. The specific results can be outlined as follows: a high proportion of students to continue their studies, with substantial number of students entering well-known universities both at home and abroad after graduation. The high level of employment for undergraduates is another feature for bilingual education results. The students mostly work for well-known enterprises at home and abroad, they also have advantages in applying for government positions for civil service.

\section{Conclusion and Recommendations}

By investigation and survey, this paper filters out a certain number factors that represent the significance of the evaluation indicators. Using analytic hierarchy process and fuzzy comprehensive evaluation method, a case study is conducted on business courses of GDUFS.Quantitative analysis also applied to suitable degree of bilingual education, the aim of which is to provide a useful reference to bilingual teaching arrangements for undergraduate education majoring in International Business. When fit quantitative analysis models are established, it is critical to select the evaluation indicators. How to select the appropriate evaluation indicators based on differences in the school, discipline, curriculum, teachers and students situation, how to determine importance of these factors and how to construct the bilingual teaching evaluation index evaluation system are the problems that need further study.

The following recommendations are provided for bilingual education for the development of Chinese colleges and universities:

Establish a stable teaching team for bilingual education. Singapore, Hong Kong and other countries regard English as a second language. Due to the lack of language environment, English can only be referred to as a foreign language in China. The vast majority of foreign language teachers in China receive their education locally, so foreign language literacy is not high and two-way communication and freedom of expression and accuracy in language teaching is greatly limited. The number of teachers with both foreign language ability and high professional level in business is small in China. Relevant functional departments in universities in China should formulate reference standards for selection of bilingual teachers, confirm the identity of bilingual teachers on regular basis, create file for teaching results, develop the training plan, and organize regular training.

Firstly, teachers should be trained in teaching practice, and bilingual curriculum teaching tasks should be allocated to teachers annually. Secondly, universities must sent teachers to other foreign counterpart universities for futher study, making teacher learning by listening to lectures from other professors abroad. Thirdly, universities should encourage and support teachers to participate in the bilingual teaching research and experience exchanges. Lastly, the introduction of overseas Chinese remains a good way to rapidly improve the level of bilingual teaching faculty. Some colleges and universities have arbitrariness in the selection of bilingual teachers, and change the courses and candidates every year, which make the bilingual teaching falling into a stagnant cycle. Some universities try to develop bilingual education from scratch, and they will experience a 
process from weak to excellent. All management measures should reflect progressiveness and effectiveness of the newly established bilingual education programs in universities.

Establish reporting and verification system for bilingual education programs. Under the guidance of the relevant functional departments in the universities, the teaching units submit open plan and application report of the bilingual courses per academic year. Experts should set the feasibility of subjects and teachers that are appropriate for bilingual education, verify and confirm textbooks and related teachers which are posted officially and finally included in the business undergraduate program.

Improve the management supervision process system for the bilingual courses. In addition to regular inspection and supervision, the whole process of bilingual education should have more control: lesson planning - teaching discussion (interactive) - assignments - exams. The quality standards of bilingual teaching procedures should be developed on specific request, and teaching materials, quality of teaching notes, choice of language of instruction and teaching tasks should be regularly checked. Other terms should be included in the teaching procedures and evaluation criteria, such as "specifications in bilingual education, the percentage of lectures and interactive in English above 50\%, assignments and tests that delivered in English is up to 50\%". Universities cannot be fully applied practice of other peers, but clear and consistent standards and concepts should be applied.

Regular bilingual teaching competition, phased comments organizational experts, peer supervision and observe appraisal should be held, which is an important means to promote the construction and development of bilingual education system in Chinese universities. Special incentive mechanism should also be maintained, because bilingual teaching staff performance incentives are important part of the management chain in the teaching process. More returns or bonus on bilingual teaching is conducive to make the courage and enthusiasm for the work of instructors, thereby enhancing the quality of teaching level and results. Bilingual teachers should occupy significant parts or priority in the work of the performance assessment, appraisal standards, and study abroad for teachers.

Many universities are still in the initial stage of experiments on bilingual education in China. They are exploring new management mode, provide substantial support and make efforts to find out a suitable way for bilingual education for their own. This paper tries to provide some hints for the further development of bilingual education in universities in China.

\section{References}

Chen. X. C. (2006). Research on evaluation on bilingual education. Shanghai: MA dissertation of Shanghai Normal University.

Doyle, W. (1986). Classroom organization and management. In M. Wittrock (Ed.), Handbook of research on reaching (3rd ed. pp. 354-395). Upper Saddle River, NJ: Merrill/ Prentice Hall.

Dornyei, Z., \& Kormos, J. (1998). Problem-solving mechanisms in L2 communication: A psycholinguistic perspective. Studies in Second Language Acquisition, 20(3), 349-385. http://dx.doi.org/10.1017/S0272263198003039

Fan, X. Y., \& Zheng, J. G. (2006). Billingual education model in higher education in China. Journal of Donghua University (Social Science Edition), 6(3), 66-69.

Grant, H. (1987). A Guide to Language Testing: Development Evaluation and Research (pp. 143-155). Thomson Learning Press.

Huang, Q. (2007). Implications of Anglo-American higher education evaluation to the evaluation of college English teaching in China. Research Management, 1, 56-69.

Hunkins, F. (1989). Teaching thinking though effective questioning. Boston: Christopher-Gordon.

Jia, X. H. (2008). Bilingual Teaching of International Economics and Trade. Modern Economic Information, 4, 78-90.

Liu, Z. Z. (2007). Analysis on effectiveness of bilingual teaching based on students' individual differences International Economics. Education Forum, 9, 98-117.

Merrill, S. S. (1985). Evaluation Bilingual Education: A Canadian Case Study (pp. 16-30). Multilingual Matters Ltd.

Rao, H. (2009). Design and implementation of bilingual teaching evaluation system based on RBF neural network. Journal of Nanchang University, 4, 56-64.

Sang, Q. B. (2010). Bilingual education evaluation system based on neural network. Journal of Jiangnan 
University, 3, 25-32.

Yang, J. S. (2005). Reflections on the construction of a bilingual education- "study • teach" evaluation system. Journal of Shanghai Polytechnic University, 6, 58-68.

Yang, X. Y. (2007). Analysis and effectiveness survey on bilingual teaching. Journal of Peking University, 5, 90-102.

Zhang, J. (2007). On the Bilingual Teaching Evaluation System Construction. Probe in Higher Education, 2, 67-73.

Zhu, L. L. (2008). Bilingual teaching quality evaluation based on Fuzzy-AHP. Agriculture Education in Higher Education, 3, 78-86.

Zhu, Z. H. (2009). Evaluation system of vocational bilingual teaching on job skills perspective. Helongjiang Education, 4, 90-98.

\section{Copyrights}

Copyright for this article is retained by the author(s), with first publication rights granted to the journal.

This is an open-access article distributed under the terms and conditions of the Creative Commons Attribution license (http://creativecommons.org/licenses/by/3.0/). 